\title{
Research on quality evaluation of landslide forecast model
}

\author{
Zhaoyang Wang \\ College of Geology \& Environment, Xi'an University of Science and Technology, Xi'an 710054, \\ China \\ wangzhaoyang1999@126.com
}

\begin{abstract}
Keywords: landslide forecast; fitting effect; experiment forecast effect; quality evaluation
Abstract. In recent years, At home and abroad scholars proposed a great deal of mathematical models on landslide forecast, which through the fitting of landslide monitoring data and trend analysis to determine the landslides time. How to determine the results of the analysis to different mathematical models and identify good and bad quality of the forecast model is an important problem to the landslide forecast and decision-makers. The author proposed fitting effect index(including posterior index, model fitting efficiency index and RMS error) and experiment forecast effect index(including experiment forecast index and related coefficient index), which establishment quality testing model of landslide forecast. Using gray GM $(1,1)$ mathematical model, the three exponential smoothing model and time series model fit and experiment forecast the monitoring data of Lianziya dangerous rock body in the three gorges of the Yangtze river. Using fitting effect index and experiment forecast effect index comprehensive analysis, the results showed the quality testing model of landslide forecast is an effective and practical approach.
\end{abstract}

Landslide forecast research has become a hot topic from the 1960s (Xu et al.,2004; Yang et al.,2004;. Li et al.,1999; Huang et al.,2004; Yin. 2004 ; Wen et al.,2004). In recent years, Experts and scholars from home and abroad have done a lot of research work at the time of landslide forecasting, which made a variety of landslide forecasting model, such as the gray forecast model(Li et al.,2007; Lu et al.,2001; Wang et al.,2005), neural network model (Lin et al.,2002; K.M. et al.,2004), and so on(Li et al.,1996; Yi et al.,2007; Xie et al.,2005). Various forecasting methods has its own advantages, but also there is a corresponding shortcomings and deficiencies. Most forecasting models are based on the monitoring of landslide displacement data were fitted speculate as to how to assess the quality of the forecasting model is good or bad, it becomes a problem for landslide forecast researchers and policy-makers to be solved.

A good forecasting model is not only to be able to describe the past events, more important it is to be able to predict future events. Thus, for quality assessment of landslide forecasting model it is absolutely necessary. We can assess the quality of the model, in order to truly establish forecasting model in line with the actual conditions of the landslide, and reliable forecasting results. In this paper, by using the fitting and forecasting performance metrics to fully assess the quality of both the effects of landslide prediction model.

\section{Quality inspection of the landslide forecast model}

\section{Fitting performance metrics}

Fitting effect index is forecasting model fits the data sequence and the average deviation from the actual measurement data sequence to measure the fitting accuracy of the forecasting model.

\section{Posterior variance index $(P, C)$ (Deng. 1987)}

In the residual prediction mode, the number of tests is not counted out all at once, but after the previous data is calculated by a data, so turn recursion tests, each test is a test value for value models, so after the test referred to here as posterior inspection.

Let $k$ moment of actual measurement data is $x^{(0)}(k)$, the predictive value of $\hat{x}^{(0)}(k)$ at that time, the difference between the two is $q(k)$.

$$
q(k)=x^{(0)}(k)-\hat{x}^{(0)}(k)
$$


$q(k)$ is called $k$ time residuals.

The actual monitoring data variance $s_{1}^{2}$

$$
S_{1}^{2}=\frac{1}{n} \sum_{k=1}^{n}\left(x^{(0)}(k)-\bar{x}\right)^{2}
$$

Residual variance

$$
S_{2}^{2}=\frac{1}{n} \sum_{k=1}^{n}(q(k)-\bar{q})^{2}
$$

Where $\bar{x}=\frac{1}{n} \sum_{k=1}^{n} x^{(0)}(k) \quad \bar{q}=\frac{1}{n} \sum_{k=1}^{n^{\prime}} q(k), \quad n^{\prime}<n$

The difference in the ratio of $C$ for the posterior two important test of the posterior variance data $P$ and the small probability of error.

$$
\begin{aligned}
& C=\frac{S_{2}}{S_{1}} \\
& P=P\left\{|q(k)-\bar{q}|<0.6745 S_{1}\right\}
\end{aligned}
$$

Indicators $C$ the smaller the better. $C$ smaller, then the larger $S_{1}$ and $S_{2}$ is smaller. $S_{1}$ large value, indicating that the original data variances large, large degree of dispersion of the original data. $S_{2}$ small, indicating that the residual variance small, residual degree of dispersion. $C$ small, indicating that even if the original data is discrete, and the resulting model to calculate the difference between the actual value of not very discrete. $P$ additional indicators the better. $P$ greater, indicating that the average difference between the residual and the residual value is less than the given $0.6745 S_{1}$ points more.

On the basis of two indicators $C$ and $P$ can be integrated assessment of the accuracy of the prediction model. Specific indicators as shown in Table 1.

\begin{tabular}{lcc}
\multicolumn{3}{c}{ Table 1 The reference table of precision check grade } \\
$\begin{array}{lcc}\text { Prediction accuracy } \\
\text { class }\end{array}$ & $P$ & $C$ \\
\hline good & $>0.95$ & $<0.35$ \\
better & $>0.8$ & $<0.5$ \\
qualified & $>0.7$ & $<0.5$ \\
failure & $\leq 0.7$ & $<0.45$
\end{tabular}

\section{The model fit efficiency index $(E F)$}

$\geq 0.65$

Using the model fit efficiency index numerical size $E F$ to evaluate the accuracy of the model simulation. $E F$ is determined by the following formula.

$$
E F=\left[\sum_{i=1}^{n}\left(y_{i}-\bar{y}\right)^{2}-\sum_{i=1}^{n}\left(y_{i}-\hat{y}_{i}\right)^{2}\right] / \sum_{i=1}^{n}\left(y_{i}-\bar{y}\right)^{2}
$$

The maximum value of $E F$ is 1 , then the predictive value of $\hat{y}$ and $y$ observations in full compliance, namely $\sum_{i=1}^{n}\left(y_{i}-\hat{y}_{i}\right)^{2}=0$. If value of $E F$ is negative, indicating that the model is inappropriate. Value of $E F$ is closer to 1, indicating which good value, range 0 to 1 .

\section{Root mean square error ( $R M S E$ )}

RMS error is also known as the standard error, which is a common method of fitting error analysis, the formula is

$$
R M S E=\sqrt{\frac{1}{n} \sum_{t=1}^{n}\left(y_{t}-\hat{y}_{t}\right)^{2}}
$$


RMSE is RMS value; monitoring the time value of $t$ is $y_{t}, \hat{y}_{t}$ for the model fit the time value of $t, n$ is the number of hours of monitoring. RMSE value is smaller, the better the effect that the model fit.

\section{Test performance metrics forecast}

Final inspection forecasting model requires after the forecasting event can be done. In order to verify the effect of the model, we can use the results of the model test report conducted tests to determine the reliability of forecasting models. When using the actual monitoring data to establish forecasting model, it may be reserved five or more actual monitoring data for testing the effect of the test report.

\section{Test report performance metrics $(E)$}

Set $E$ as test forecasting performance metrics, then

$$
E=\frac{N}{L} \times 100 \%
$$

$N$ is trial forecasting the relative error test less than $15 \%$ of the number forecasting. $L$ is the total number of test forecasts.

Relative error of trial forecasting is e.

$$
e_{i}=\frac{\left|\hat{H}_{i}-H_{i}\right|}{H_{i}} \times 100 \%
$$

Numerical value $E$ of trial performance metrics forecasting can basically reflect the effect of forecast models predict. The greater the value of $E$, the results show that the reliability of forecasts and forecast accuracy is relatively high.

The correlation coefficient $(r)$

By correlation coefficient calculation model between forecast values $\hat{y}_{i}$ and actual values $y_{i}$, it can reflect the degree of linear correlation between the forecast and the actual situation of the case.

The correlation coefficient $r$ is calculated as follows

$$
r=\frac{\sum_{i=1}^{N}\left(\hat{y}_{i}-\overline{\hat{y}}\right)\left(y_{i}-\bar{y}\right)}{\sqrt{\sum_{i=1}^{N}\left(\hat{y}_{i}-\overline{\hat{y}}\right)^{2} \sum_{i=1}^{N}\left(y_{i}-\bar{y}\right)^{2}}}
$$

Where $\mathrm{N}$ is the total number of forecast, $\hat{y}_{i}$ is the $i$ years of forecasting value, $y_{i}$ is the $i$ years of the actual monitoring values.

$r$ larger absolute value, the higher the degree of correlation forecasting and monitoring actual values between the values.

\section{Comprehensive assessment index}

A good forecast model should be a fitting and comprehensive forecast of optimal configuration, therefore, we need to be integrated weighting function to fit the indicators and predictors of comprehensive determination. There are four indicators fitting indicators, namely the posterior variance ratio, a small error probability model efficiency and root mean square error. Forecast index has two index, that is test report performance metrics and correlation index. Denoted composite index, Fit index weights are 0.4, 0.6 forecast index, calculated by the formula index.

$S$ represents the composite index, which fitting index weight is 0.4 and forecasting index is 0.6 . We can use the following formula to calculate the composite index.

$$
S=0.4 \times(P+E F+1 / C+1 / R M S E)+0.6 \times(E+|r|)
$$

)

The calculated $S$ values greater, indicating a better quality of the forecasting model than the other models. We can recommend the use of the model for landslide prediction. 


\section{Examples of verification}

Select literature (Li et al., 2001) Lianziya hazard rock mass 1978 points - displacement monitoring data in 1988 were analyzed. Select three forecasts model, gray GM $(1,1)$ model, cubic exponential smoothing and time series (AR) model simulation were forecasting, simulation, time period from 1978 to 1984 , forecast period 1985 to 1988. Displacement monitoring and each model simulation to predict the results in Table 2.

Table 2 Displacement simulation-forecast results of each model in Lianziya hazard rock $\operatorname{mass}\left(\mathbf{G}_{\mathbf{A}}\right)$

\begin{tabular}{|c|c|c|c|c|c|c|c|}
\hline $\begin{array}{c}\text { time } \\
\text { ( year/month ) }\end{array}$ & $\begin{array}{l}\text { Measured } \\
\text { value } \\
\text { /mm }\end{array}$ & GM(1,1)model & $\begin{array}{l}\text { Relative } \\
\text { error } 1 \%\end{array}$ & $\begin{array}{c}\text { Three } \\
\text { exponential } \\
\text { smoothing }\end{array}$ & $\begin{array}{l}\text { Relative } \\
\text { error } 1 \%\end{array}$ & $\begin{array}{c}\text { Sequentially } \\
\text { (AR ) } \\
\text { model }\end{array}$ & $\begin{array}{l}\text { Relative } \\
\text { error } 1 \%\end{array}$ \\
\hline
\end{tabular}

$\begin{array}{llcccccc}1978.12 & 10.32 & 10.320 & 0.00 & 11.602 & 12.42 & 16.901 & 63.77 \\ 1979.12 & 26.96 & 33.531 & 24.37 & 11.706 & -56.58 & 20.330 & -24.59 \\ 1980.12 & 34.07 & 35.480 & 4.14 & 31.423 & -7.77 & 29.930 & -12.15 \\ 1981.12 & 38.65 & 37.542 & -2.87 & 41.542 & 7.48 & 36.163 & -6.43 \\ 1982.12 & 42.98 & 39.724 & -7.58 & 45.352 & 5.52 & 41.503 & -3.44 \\ 1983.12 & 44.93 & 42.033 & -6.45 & 47.887 & 6.58 & 46.754 & 4.06 \\ 1984.12 & 47.16 & 44.477 & -5.69 & 47.724 & 1.20 & 51.164 & 8.49 \\ 1985.12 & 48.38 & 47.062 & -2.72 & 48.284 & -0.20 & 55.673 & 15.07 \\ 1986.12 & 49.95 & 49.797 & -0.31 & 48.287 & -3.33 & 62.402 & 24.93 \\ 1987.12 & 51.75 & 52.692 & 1.82 & 47.264 & -8.67 & 68.501 & 32.37 \\ 1988.12 & 52.50 & 55.755 & 6.20 & 45.215 & -13.88 & 74.377 & 41.67\end{array}$

We calculate the fitting indicators and forecasts for each indicator forecasting model, then composite index is calculated, the last model to predict the quality of test results $S$ obtained, are shown in Table 3.

Table 3 Quality inspection result of each model

\begin{tabular}{|c|c|c|c|c|c|c|c|}
\hline \multirow[t]{2}{*}{ Forecast Model } & \multicolumn{4}{|c|}{ Fit Index } & \multicolumn{2}{|c|}{ Forecast Index } & \multirow{2}{*}{$\begin{array}{c}\begin{array}{c}\text { Composite } \\
\text { Index }\end{array} \\
S\end{array}$} \\
\hline & $P$ & $C$ & $E F$ & $R M S E$ & $E$ & $|r|$ & \\
\hline $\operatorname{GM}(1,1)$ model & 1 & 0.1722 & 0.9746 & 2.056 & $25 \%$ & 0.981 & 4.046 \\
\hline $\begin{array}{l}\text { Three exponential } \\
\text { smoothing } \\
\text { Sequentially (AR) }\end{array}$ & $\begin{array}{l}0.86 \\
1\end{array}$ & $\begin{array}{l}0.506 \\
0.3628\end{array}$ & $\begin{array}{l}0.7351 \\
0.8676\end{array}$ & $\begin{array}{l}6.146 \\
4.34\end{array}$ & $\begin{array}{l}100 \% \\
25 \%\end{array}$ & $\begin{array}{l}0.849 \\
0.991\end{array}$ & $\begin{array}{l}2.603 \\
2.686\end{array}$ \\
\hline
\end{tabular}

From the above table 3 , each forecast model results, the comprehensive index GM $(1,1)$ the highest value, in order to adopt the recommendations of the landslide GM $(1,1)$ to forecast, model quality and better than the three time-series exponential smoothing effect.

\section{Conclusion}

(1) Quality inspection by the landslide forecast model fitting performance metrics (including the posterior variance index, efficiency index model and RMSE) and try forecasting performance metrics (performance and correlation coefficient test report) together form.

(2) By way of example calculations show that for landslide prediction model fitting results using indicators and forecast performance metrics common test, available forecasting models forecasting higher confidence. 
(3) Landslide forecast quality evaluation is an effective and practical means for landslide prediction model evaluation, after the landslide prediction model for the assessment need to be further improved and perfected.

\section{Reference}

[1] XU Qiang, HUANG Run-qiu, LI Xiu-zhen. Research progress in time forecast and forecast of landslides. Advance in earth sciences , 2004, 19(3) : 478-483.

[2] YANG Zhi-fa, CHEN Jian. Thoughts on the forecast or forecast of landslides. Journal of Engineering Geology, 2004, 12(2): 118-123.

[3] LI Tian-bin, CHEN Ming-dong, WANG Lan-sheng. Real-time tracing forecast of landslides[M]. Chengdu: chengdu university of science and technology press, 1999.

[4] HUANG Run-qiu. On time predication of landslide. Scientific and Technological Management of Land and Resources , 2004, (6):15-20.

[5] YIN Kun-long. Landslide hazard forecast and evaluation. Beijing: China University of Geosciences Press, 2004.

[6] WEN Hai-jia, ZHANG Yong-xing, LIU Yuan. At home and abroad investigation tendency of landslide forecast. The Chinese Journal of Geology Hazard and Control, 2004 , 15(1) : 2-4.

[7] LI Xiu-zhen , KONG Ji-ming, WANG Cheng-hua. Comparison and application of gray GM(1,1) modified residual error models in landslide predicting. Journal of mountain science, 2007 , 25(6): 741-746.

[8] LU Li-shun, ZHU Hai-jun. application of grey model in landslide time forecast. Water Resources \& Hydropower of Northeast China, 2001 , 19 ( 207 ) : 50-52.

[9] WANG Li, ZHANG Shuang-cheng, LI Ya-hong. Application of dynamic grey forecast model in dam deformation monitoring and forecast. Journal of Xi'an university of science and technology, 2005,25 ( 3 ) : 328-332.

[10] LIN Lu-sheng, FENG Xia-ting, BAI Shi-wei, et al. Application of artificial neural network to forecast of sliding slope. Rock and Soil Mechanics, 2002 , 23(4): 508-510.

[11] K.M.Neaupane, S.H.Achet. Use of backpropagation neural network for landslide monitoring: a case study in the higher Himalaya. Engineering Geology, 2004, 213-226.

[12] Li T B, Cheng M D. Time forecast of landslides using the Verhulst inverse function model. In: Proc. $7^{\text {th }}$ Intern. Symp. on landslides. Rotterdam: A.A.Balkema Publichers, 1996.

[13] YI Guang-zhi, ZHANG Wei-zhong, ZHANG Dong-ming, et al. Foecasting of landslide displacement based on exponential smoothing and nonlinear regression analysis. Rock and Soil Mechanics, 2007 , 28 ( 8 ) : 1725-1728.

[14] XIE Feng, ZHU Lu-ming, WANG Li-zhong. Modified grey system forecast model and its application for analyzing information of landslide monitory. Chinese Journal of Rock Mechanics and Engineering, 2005 , 24(22):4099-4105.

[15] DENG Ju-long. Basic method of gray system. Wuhan: Huazhong university of science and technology press, 1987.

[16] LI Xiao-hong, JIN Xiao-guang, KANG Hui-ming, et al. Application of GM(1,1) majorized model to simulation-forecast of landslide. Journal of mountain science, 2001, 19 ( 3 ) : 265-269. 